Fluoroscopically guided percutaneous

\section{gastrostomy in patients with cystic fibrosis}

\author{
R F McLoughlin, G O'Connor, \\ J Dowsett, M X Fitzgerald, \\ R G Gibney
}

\begin{abstract}
The feasibility of fluoroscopically guided percutaneous gastrostomy in patients with cystic fibrosis is presented, highlighting differences between these and other patients undergoing the procedure.
\end{abstract}

(Thorax 1994;49:519-520)

Many factors affect the nutritional status of patients with cystic fibrosis. ${ }^{1}$ Undernourished patients have a poorer prognosis, ${ }^{2}$ and a recent report recommends enteral feeding in selected cases. ${ }^{1}$ While nasogastric tubes provide short term nutritional support, ${ }^{3}$ surgical enterostomy and percutaneous endoscopic gastrostomy are required for long term feeding ${ }^{45}$ which improves nutritional status in patients with cystic fibrosis. ${ }^{16}$ However, these methods require general anaesthesia or significant sedation, neither of which are desirable in patients with poor respiratory function.

Fluoroscopically guided percutaneous gastrostomy (FGPG) is a safe effective method for enteric access. ${ }^{7}$ Performed under local anaesthesia, it is particularly suited to patients with poor respiratory function, although only occasional reference has been made to its use in such cases. ${ }^{89}$ We describe our experience with FGPG in patients with cystic fibrosis.

Department of

Diagnostic Imaging

R F McLoughlin

R G Gibney

Department of Respiratory Medicine

G O'Connor

J Dowsett

M X Fitzgerald

St Vincent's Hospital, Dublin, Ireland

Reprint requests to: Dr R G Gibney.

Received 26 March 1993 Returned to authors 10 June 1993

10 June 1993

22 June 1993

Accepted for publication

16 July 1993

\section{Methods}

Six patients with cystic fibrosis referred for FGPG from November 1991 to May 1992 were prospectively studied. The referral criteria were body weight $<80 \%$ of ideal, and failure to improve with dietary counselling and oral supplements. All patients had pancreatic insufficiency.

Before the procedure pulmonary function was optimised by chest physiotherapy. All patients fasted overnight and had a nasogastric tube inserted. During the procedure the patient lay on a fluoroscopy table. The stomach was distended with air via the nasogastric tube. An entry site in the left hypo- chondrium was infiltrated with local anaesthetic and the stomach was then punctured with a Jelco 16 gauge $152 \mathrm{~mm}$ sheathed needle (Critikon). The needle was withdrawn and a $0.097 \mathrm{~cm}$ Lunderquist Ring torque guidewire (Cook) was introduced through the sheath and coiled in the stomach. The tract was dilated and the gastrostomy tube then introduced over the guidewire. An 8 French pigtail nephrostomy catheter (Cook) was used. This catheter has a loop at the end which facilitates retention within the gastric lumen.

Following gastrostomy patients ate normally by day. Using a pump, a peptide feed (Reabilan HN, Roussel) of 1000-1500 calories was delivered during the night via the gastrostomy. Patients took oral enzymes - for example, Nutrizym (E Merck Pharmaceuticals) 4-8 capsules - before and after each feed.

\section{Results}

There were four men and two women of mean age 26.6 years. The nutritional and respiratory status of the patients is outlined in table 1.

Tube placement was successful in all patients, low dose sedation being necessary in four cases. After the procedure five patients experienced pain at the gastrostomy site which required narcotic analgesia. Satisfactory feeding rates $(60-175 \mathrm{ml} /$ hour $)$ were attained in all tubes. Two patients subsequently required tube replacement for dislodgement and leakage respectively. Other problems included a case of gastro-oesophageal reflux which resolved spontaneously, and a gastrostomy site infection which responded to antibiotic therapy. Meconium ileus equivalent developed two days after the procedure in two patients (in whom there was a prompt response to treatment) and after two months in a third (in whom the response to treatment was poorer).

Four of the patients died of their underlying condition within 111 days of FGPG. In all cases tube function was maintained until the time of death or review, representing an average follow up of $20 \cdot 8$ weeks.

Details of nutritional and respiratory status before, at the time of, and after the procedure are outlined in table 2 .

\section{Discussion}

In this small series we established and maintained a functioning gastrostomy tube in all cases until the time of review or death. No major complications were encountered, and the incidence of minor complications such as tube dislodgement, leakage, and infection is similar to that among our other gastrostomy cases $^{10}$ and following surgical enterostomy in patients with cystic fibrosis. ${ }^{46}$

However, a number of differences were noted between this group and other patients in whom we have performed FGPG. ${ }^{10}$ Firstly, 
Table 1 Patient status at time of gastrostomy

\begin{tabular}{|c|c|c|c|c|c|c|}
\hline $\begin{array}{l}\text { Patient } \\
\text { no. }\end{array}$ & Age sex & $\begin{array}{l}\text { Weight } \\
\mathrm{kg}\end{array}$ & $\% I B W$ & $\begin{array}{l}\text { Albumin } \\
\mathrm{gl}\end{array}$ & $\begin{array}{l}F E V_{t} \\
\% \% \\
\text { predicted) }\end{array}$ & $\begin{array}{l}F V C \\
\% \\
\text { predicted }\end{array}$ \\
\hline $\begin{array}{l}1 \\
2 \\
3 \\
4 \\
5 \\
6\end{array}$ & $\begin{array}{l}28 \cdot 5 \mathrm{~F} \\
29 \cdot 5 \mathrm{M} \\
16 \cdot 3 \mathrm{M} \\
22 \cdot 9 \mathrm{M} \\
24 \cdot 0 \mathrm{M} \\
37 \cdot 4 \mathrm{~F}\end{array}$ & $\begin{array}{l}39 \\
46 \\
42 \\
42 \\
40 \\
41\end{array}$ & $\begin{array}{l}76 \\
63 \\
67 \\
69 \\
72 \\
78\end{array}$ & $\begin{array}{l}29 \\
23 \\
35 \\
42 \\
30 \\
27\end{array}$ & $\begin{array}{l}21 \\
34 \\
19 \\
30 \\
14 \\
20\end{array}$ & $\begin{array}{l}39 \\
62 \\
30 \\
34 \\
23 \\
28\end{array}$ \\
\hline
\end{tabular}

$\%$ IBW $=$ percentage of ideal body weight $\mathrm{FEV}_{1}=$ forced expiratory volume in one second FVC $=$ forced vital capacity.

Table 2 Mean (SD) nutritional and pulmonary status one year before, at time of, and after gastrostomy - that is, at time of death or final review (on average $20 \cdot 8$ weeks after gastrostomy)

\begin{tabular}{llllll}
\hline & $\begin{array}{l}\text { Before } \\
\text { gastrostomy }\end{array}$ & $p^{*}$ & $\begin{array}{l}\text { At time of } \\
\text { gastrostomy }\end{array}$ & $p^{*}$ & $\begin{array}{l}\text { After } \\
\text { gastrostomy }\end{array}$ \\
\hline Weight $(\mathrm{kg})$ & $43 \cdot 0(4 \cdot 0)$ & NS & $41 \cdot 3(1 \cdot 8)$ & NS & $43 \cdot 5(4 \cdot 5)$ \\
$\%$ IBW & $74 \cdot 5(10 \cdot 5)$ & NS & $71 \cdot 2(6 \cdot 1)$ & NS & $73 \cdot 6(3 \cdot 7)$ \\
FEV $_{1}(\%$ predicted) & $31 \cdot 5(11 \cdot 1)$ & $<0 \cdot 05$ & $22 \cdot 5(8 \cdot 0)$ & NS & $23 \cdot 0(9 \cdot 1)$ \\
FVC $(\%$ predicted) & $49 \cdot 8(13 \cdot 2)$ & $<0.05$ & $35 \cdot 0(13 \cdot 9)$ & NS & $35 \cdot 0(11 \cdot 9)$ \\
Albumin (g/l) & $37 \cdot 7(5 \cdot 1)$ & NS & $31 \cdot 3(5 \cdot 9)$ & NS & $30 \cdot 8(3 \cdot 8)$ \\
\hline
\end{tabular}

* $p$ refers to the significance of differences between the mean values before and at the time of gastrostomy, and at time of and after gastrostomy (paired Student's $t$ test).

Abbreviations as in table 1 . tation. It is therefore important to start enzyme supplementation immediately after the procedure, and it may be worth treating patients with significant faecal accumulation on plain radiography with Gastrografin before FGPG. The above findings have not been reported following gastrostomy by other methods in patients with cystic fibrosis. ${ }^{+t}$

We have documented the nutritional and pulmonary status after the procedure for completeness, but our numbers are too small to be meaningful.

In conclusion, our results show the feasibility of enteral feeding by FGPG in patients with cystic fibrosis. This, in our opinion, is the procedure of choice for long term enteral feeding in these patients, particularly those with advanced disease. We also highlight differences between patients with cystic fibrosis and others undergoing FGPG.

1 Ramsey BW, Farrell PM, Pencharz P. Nutritional assessment and management in cystic fibrosis: a consensus report. Am $\mathcal{f}$ Clin Nutr 1992;55:108-16.

2 Durie PR, Pencharz PB. A rational approach to the nutritional care of patients with CF. $\mathcal{F} R$ Soc Med $1989 ; 82: 11-20$.

3 Mansell AL, Anderson JC, Muttart CR, Ores CN, Loeff DS, Levy JS, et al. Short-term pulmonary effects of total parenteral nutrition in children with cystic fibrosis. $\mathcal{I}$ Pediatr 1984;104:700-5.

sedation is usually unnecessary, yet over half of the patients with cystic fibrosis required low dose sedation during the procedure. This is understandable as other gastrostomy candidates are often less responsive (for example, after cerebrovascular accident). Secondly, pain at the site of the gastrostomy, often severe, is more common among patients with cystic fibrosis. This may be related to coughing associated with underlying lung disease. Finally, meconium ileus equivalent developed after gastrostomy in three of our patients. This may have been precipitated by gastrostomy tube insertion, change in diet to a peptide feed, or inappropriate pancreatic enzyme supplemen- 